\title{
In Memoriam: Myriam Sarachik
}

\author{
Tony Liss \& Parameswaran Nair
}

$\mathrm{O}$ UR DEAR COLlEague Myriam Sarachik passed away on October 7, 2021, leaving a void in the hearts of everyone she touched in the City College of New York physics department, where she was its most distinguished member, and at the college itself, which she loved and which loved her right back.

Myriam wrote about her life in a prefatory piece for Annual Reviews of Condensed Matter Physics in 2018. ${ }^{1}$ She was born Myriam Morgenstein to a large Orthodox Jewish family in Antwerp in 1933, the year of Adolf Hitler's rise to power. Hitler's ascendancy set the trajectory of Myriam's life. In 1941, her immediate family attempted to follow the rest of the extended family in fleeing from Nazi-occupied Belgium through occupied France, and then, using forged exit permits, into northern Spain and on to Cuba. Having departed just a day after the rest of the family, they were denied entry into Spain because authorities had been alerted to their forged exit permits. After trying to sneak in with the help of a smuggler, they were apprehended and sent to an internment camp near Bordeaux and then to another camp near Tours. After a short time, they escaped and were smuggled into Vichy France and eventually into Spain. From there they sailed to Havana to join the rest of the family at the end of 1941, arriving shortly before the attack on Pearl Harbor. ${ }^{2}$

Myriam lived in Cuba between the ages of eight and thirteen. Having grown up speaking Yiddish, she learned Spanish and then English. She also learned the piano and trained with the Cuban national swim team. While the war raged in Europe, Myriam noted, "I grew up on a beautiful island, in a sunny, idyllic environment-lush, beautiful, serene, a haven away from the chaos and the carnage."3

In 1947, her family moved to the United States; Myriam attended the Bronx High School of Science. Steven Weinberg and Sheldon Lee Glashow were in her class, as well as Daniel Greenberger, who would become Myriam's colleague at City College. This group was the high school class equivalent of the 1927 Yankees team.

Myriam enrolled at Barnard College, but took physics classes at Columbia University, since science was mostly a man's profession. She was undeterred by this obstacle, and remained undeterred by similar obstacles throughout her life and career. During this time, she worked summers at Bell Labs, where she was paid two-thirds of what her male classmates made. Upon graduation from college, she was discouraged from pursuing a career in physics, but she persevered, working first at the IBM Watson Laboratory and then attending graduate school at Columbia.

Despite her interest and skill in physics, graduate school was not an obvious step for women at the time and especially not for one, like Myriam, from an Orthodox Jewish background. In the summer after she graduated from Barnard, Myriam married the love of her life, Phil Sarachik, an engineer. They had first met in freshman physics. Phil encouraged her to go to graduate school, and after their first daughter Karen was born, encouraged her to look for a job in physics, despite the difficulty of raising a child with two working parents. While looking for a full-time job in 1962, Myriam encountered stiff resistance to the idea that physics was an appropriate career for any woman, much less a woman with a newborn. She eventually landed a position as a member of the technical staff at Bell Labs with the help of Polykarp Kusch, one of her professors from Columbia, but only after "maybe a half hour arguing about it-because he didn't think I should be looking for a full-time job."

It was at Bell Labs that Myriam began to flourish as a scientist, but she was a postdoc there, and, like most Bell Labs postdocs, she had only a two-year appointment. Myriam searched for a full-time faculty position, but was offered only part-time positions or a second postdoc. Erich Erlbach, who had been a fellow graduate student, had gone from IBM to City College. When Myriam applied to City College, Erlbach was her enthusiastic supporter, and City College offered Myriam a full-time faculty position. Famous for providing opportunities to students from immigrant and refugee families, City College was the only place that offered the immigrant refugee, Myriam Sarachik, a full-time faculty position. One of the reasons she was so dedicated to City College is that her story was so much like the stories of its students.

Myriam thrived at City College and was promoted to associate professor with tenure in just three years, and to full professor three years after that. One of her early notable achievements was finding experimental confirmation for what would later be known as the Kondo effect, a resistivity minimum in certain alloys containing mag- 
netic impurities. Experiments showed that the minimum occurred only at low temperatures, with Myriam's data providing conclusive evidence. ${ }^{5}$ Jun Kondo's explanation of the effect relied on these observations. ${ }^{6}$

In 1970, Myriam's career was almost derailed by the tragic death of her second daughter, Leah, who was born shortly after Myriam's arrival at City College. Leah was kidnapped and murdered by her babysitter. It was not until ten years later that Myriam returned to her research. That she was able to recover from such a tragedy is remarkable. That she was later able to rejoin her field, and, after a significant struggle, begin what she called "the most productive (25-year) period of my life, starting when I was in my early 50s," is also nothing short of remarkable. ${ }^{7}$

In the 1980s, Myriam and her collaborators carried out a long series of experiments on metal-insulator transitions, measuring critical exponents as they approached transition. Their work during this period yielded a major breakthrough on two-dimensional metal-insulator transitions. Working separately in Russia, Sergey Kravchenko had obtained some suggestive, but not definitive, data indicating the possibility of such a transition. The prevailing view, based on work by Nobel laureate Philip Anderson and others, was skeptical. Myriam remained open-minded and invited Kravchenko to City College. Together they carried out measurements that provided incontrovertible evidence of the phenomenon. ${ }^{8}$ This finding triggered a wave of new research by many different groups, both theoretical and experimental.

In the 1990s, Myriam carried out another long series of experiments on the macroscopic quantum tunneling of magnetization. Collaborating with theorists and other experimentalists, she was able to demonstrate the existence of this phenomenon in molecular magnets. ${ }^{9}$ As part of these investigations, her group discovered a new and unexpected effect known as magnetic deflagration, or magnetic avalanche, which is characterized by an explosive relaxation of magnetization approaching thermal equilibrium. These results opened up entirely new lines of experimental work.

Although her work on the Kondo effect, the metal-insulator transition, and the quantum tunneling of magnetization are clear highlights in Myriam's research career, she had a lifetime of first-rate work that was recognized through numerous awards. Some highlights include her election to the National Academy of Sciences (1994); the Oliver E. Buckley Prize in Condensed Matter Physics from the American Physical Society (APS) (2005); the L'Oréal-UNESCO For Women in Science Award for North America (2005); and becoming the first, and so far only, woman awarded the APS Medal for Exceptional Achievement in Research (2020). In 2003, Myriam became the third woman elected president in the more than one-hundred-year history of the APS.

Myriam was a wonderful person. Whether it was about physics, politics, art, or theater, conversations with her were always a delight. She had a playful yet sober optimism; she recognized that things could go bad-understandable given her life story-but felt there was no point in being overly concerned in advance. She was fond of saying, "We may have to jump off the bridge, we'll do it when we get there." In the meantime, we can work to avoid it.

Tony Liss is an experimental high energy physicist currently serving as Provost and Senior Vice President for Academic Affairs at the City College of New York.

Parameswaran Nair is a Distinguished Professor of Physics at the City College of New York.

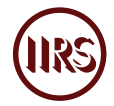

1. Myriam Sarachik, "Pushing Boundaries: My Personal and Scientific Journey," Annual Review of Condensed Matter Physics 9 (2018): 1-15, doi:10.1146/annurev-conmatphys033117-054029.

2. Sarachik, "Pushing Boundaries."

3. Sarachik, "Pushing Boundaries."

4. Interview with Myriam Sarachik by David Zierler, September 15, 2020, American Institute of Physics, Oral History Interviews.

5. Myriam Sarachik, abstract in 9th Conference on Magnetism and Magnetic Materials, Atlantic City, NJ, Nov. 12-15 (Amsterdam: Elsevier, 1963).

6. Jun Kondo, "Resistance Minimum in Dilute Magnetic Alloys," Progress of Theoretical Physics 32, no. 1 (1964): 37-49, doi:10.1143/PTP.32.37.

7. Sarachik, "Pushing Boundaries."

8. Sergey Kravchenko et al., "Electric Field Scaling at a $B=0$ Metal-Insulator Transition in Two Dimensions," Physical Review Letters 77, no. 24 (1996): 4,938-41, doi:10.1103/Physrevlett.77.4938.

9. Jonathan Friedman et al., "Macroscopic Measurement of Resonant Magnetization Tunneling in High-Spin Molecules," Physical Review Letters 76, no. 20 (1996): 3,830-33, doi:10.1103/PhysRevLett.76.3830.

DOI: $10.37282 / 991819.22 .7$ 